\title{
Erratum: Activation of neutrophils by autocrine IL-17A-IL-17RC interactions during fungal infection is regulated by IL-6, IL-23, ROR $\gamma$ t and dectin-2
}

Patricia R Taylor, Sanhita Roy, Sixto M Leal Jr, Yan Sun, Scott J Howell, Brian A Cobb, Xiaoxia Li \& Eric Pearlman

Nat. Immunol. 14, 143-151; published online 22 December 2013; corrected after print 29 January 2014

In the version of this article initially published, the far right labels in Figure 2d,e were truncated. The correct label for each is ' $R o r c$ GFP/GFP', Also, a sentence was missing from the Flow Cytometry subsection of the Online Methods section. That subsection should begin as follows: "Neutrophils were incubated for $2 \mathrm{~h}$ at $37^{\circ} \mathrm{C}$ and $5 \% \mathrm{CO}_{2}$ with a brefeldin-monensin 'cocktail' (Protein Transport Inhibitor Cocktail; eBioscience) during in vitro stimulation. Total bone marrow cells..." The errors have been corrected for the HTML and PDF versions of this article.

\section{Erratum: Quantitative and temporal requirements revealed for Zap70 catalytic activity during $T$ cell development}

Byron B Au-Yeung, Heather J Melichar, Jenny O Ross, Debra A Cheng, Julie Zikherman, Kevan M Shokat, Ellen A Robey \& Arthur Weiss Nat. Immunol. 15, 687-694 (2014); published online 8 June 2014; corrected online 23 June 2014

In the version of this article initially published online, the second sentence of the legend to Figure 6e was incorrect. It should read "HXJ42 ( $1 \mu \mathrm{M})$ was added.... The error has been corrected in the HTML version of this article.

\section{Corrigendum: $\mathrm{T}_{\mathrm{H}} 9$ cells that express the transcription factor PU.1 drive T cell-mediated colitis via IL-9 receptor signaling in intestinal epithelial cells}

Katharina Gerlach, YouYi Hwang, Alexej Nikolaev, Raja Atreya, Heike Dornhoff, Stefanie Steiner, Hans-Anton Lehr, Stefan Wirtz, Michael Vieth, Ari Waisman, Frank Rosenbauer, Andrew N J McKenzie, Benno Weigmann, Markus F Neurath Nat. Immunol. 15, 676-686 (2014); published online 8 June 2014; corrected after print 21 August 2014

In the version of this article initially published, the labels along the horizontal axes of the graphs Figure $6 \mathrm{e}, \mathrm{f}$ (right), indicating the presence or absence of IL-9, are reversed. Each '-' should be '+', and each '+' should be '-'. The error has been corrected in the HTML and PDF versions of this article.

Corrigendum: Inducible nitric oxide synthase is a major intermediate in signaling pathways for the survival of plasma cells

Ankur S Saini, Gautam N Shenoy, Satyajit Rath, Vineeta Bal \& Anna George

Nat. Immunol. 15, 275-282 (2014); published online 19 January 2014; corrected after print 21 August 2014

In the version of this article initially published, Figure $6 \mathrm{a}, \mathrm{b}$ lacked asterisks to indicate $P$ values. The error has been corrected in the HTML and PDF versions of the article.

Corrigendum: Transcriptional programs of the lymphoid tissue capillary and high endothelium reveal control mechanisms for lymphocyte homing

Mike Lee, Helena Kiefel, Melissa D LaJevic, Matthew S Macauley, Edward O'Hara, Junliang Pan, James C Paulson \& Eugene C Butcher Nat. Immunol. 15, 982-995 (2014); published online 31 August 2014; corrected after print 27 October 2014

In the version of this article initially published, Hiroto Kawashima was omitted as an author. The correct author list is as follows: Mike Lee ${ }^{1}$, Helena Kiefel $^{1}$, Melissa D LaJevic ${ }^{1}$, Matthew S Macauley ${ }^{2}$, Hiroto Kawashima ${ }^{3}$, Edward O’Hara ${ }^{4}$, Junliang Pan ${ }^{4}$, James C Paulson ${ }^{2}$ \& Eugene C Butcher ${ }^{1,4,5}$. The affiliation for this author is as follows: Department of Biochemistry, School of Pharmacy and Pharmaceutical Sciences, Hoshi University, Tokyo, Japan. The Author Contributions section should include "H.K. provided advice and the S2 hybridoma" (and the corresponding first thanks in Acknowledgments should be removed). The error has been corrected in the HTML and PDF versions of the article. 